\title{
Evolutionary Progress: Stephen Jay Gould’s Rejection and Its \\ Critique
}

\author{
LI Jianhui \\ Beijing Normal University, Beijing, China
}

\begin{abstract}
In evolutionary theory, we generally believe that the evolution of life is from simple to complex, from single to diverse, and from lower to higher. Thus, the idea of evolutionary progress appears obvious. However, in contemporary academic circles, some biologists and philosophers challenge this idea. Among them, Gould is the most influential. This paper first describes Gould’s seven arguments against evolutionary progress, i.e., the human arrogance argument, anthropocentric argument, no inner thrust argument, no biological base argument, extreme contingency argument, statistical error argument, and bacteria (other than human beings) ruling the earth argument. Gould's arguments against evolutionary progress have great influence in contemporary evolutionary theory. Thus, it is necessary to conduct a careful philosophical analysis of each of Gould's arguments to reveal his philosophical mistakes. This research contends that Gould's arguments against evolutionary progress are invalid.
\end{abstract}

Keywords: evolution, evolutionary progress, natural selection, Stephan Jay Gould

\section{Introduction}

In evolutionary theory, we often have the impression that the evolution of life is from simple to complex, from single to diverse, and from lower to higher. Hence, it seems obvious that evolution is progressive. At the end of On the Origin of Species, Darwin wrote: "as natural selection works solely by and for the good of each being, all corporeal and mental endowments will tend to progress towards perfection” (Darwin, 1859, p. 489). This evolutionary view can also be seen in these words of Darwin:

Thus, from the war of nature, from famine and death, the most exalted object which we are capable of conceiving, namely, the production of the higher animals, directly follows. There is grandeur in this view of life, with its several powers, having been originally breathed into a few forms or into one; and that, whilst this planet has gone cycling on according to the fixed law of gravity, from so simple a beginning endless forms most beautiful and most wonderful have been, and are being, evolved. (Darwin, 1859, p. 490)

After Darwin, from Ernst Haeckel down to Julian Huxley, J. M. Thoday, M. D. Sahlins, E. R. Service, C. J. Herrick, G. G. Simpson, F. J. Ayala, E. O. Wilson, and Richard Dawkins, ideas of evolutionary progress have ridden high. However, in contemporary academic circles, some biologists and philosophers, such as J. Haldane, George C. Williams, Stephan Jay Gould, T. A. Goudge, David Hull, and Michael Ruse, challenge this idea.

Acknowledgement: This research is financially supported by the research project of National Social Science Foundation of China: "Key Problems in Philosophy of Biology" (14ZDB171).

LI Jianhui, Ph.D., professor, School of Philosophy, Beijing Normal University, Beijing, China; Beijing Normal University-Hong Kong Baptist University United International College, Zhuhai, Guangdong Province, China. 
They either believe that Darwin himself rejected evolutionary progress, for he opposed to use of such words as "lower" and "higher", or contend that the idea of progress is anthropocentric and subjective because in nature there is no so-called progress in biological evolution. Of them, Gould is the most influential, providing systematical theories and arguments to oppose evolutionary progress.

Gould was a well-known American evolutionary biologist, paleontologist, historian of science, and scientific essay writer at Harvard University. His early research area was the natural history of snails, but he became renowned in science for the theory of punctuated equilibrium, which he developed with Niles Eldredge in 1972. The theory, unlike Darwin's or new Darwinians', who believe that evolution is marked by a pattern of slow and continuous changes, proposes that evolution is a process of long periods of stability or invariability punctuated by swift and violent changes. After the establishment of his status and prestige in science, Gould's other expertise began to be revealed: writing popular science and explaining the influence of evolution on human thoughts. Beginning in 1974, he established a series titled "This View of Life" (a phrase from the concluding paragraph of Charles Darwin's Origin of Species) in the magazine Natural History. He wrote essays to describe the various thoughts inspired by biological evolution phenomena, including fanciful thoughts on life, reflections on science, and sharp critiques of social bias. These essays were later re-edited into seven books and published under the general heading of Reflections in Natural History. Most of these books were well-received. For example, Ever Since Darwin has been read by more than a million people in the United States alone and translated into many languages, including Chinese. A key idea in many of Gould's thoughts is that evolution is not directional and progressive. The idea is embodied in many of his writings and it is a recurring theme in his book Full House: The Spread of Excellence From Plato to Darwin.

Gould wrote prolifically on biology and popular science. Every one of his published books exerted extensive influence. Thus, the concept that evolution is not progress has gradually become mainstream thought and has received support from an increasing number of scholars. Many of Gould's writings have been translated into Chinese and become best-sellers, bringing their extensive influence to China. As in the West, a large number of Chinese biologists and social scientists are immediately persuaded by Gould's ideas. Many anti-progressionists even think that the translation of "evolution" as "progressive evolving" ("Jinhua") is a mistake and claim that the neutral connotation "process change" ("yanhua") is the real meaning of "evolution". However, few of Gould's arguments are valid. Thus, it is necessary to conduct a critical analysis of Gould's ideas to reveal his mistakes. Of course, after Gould's books were published, there were biologists and philosophers who criticized his mistakes. For example, Richard Dawkins (1997) notes that several of Gould's ideas are wrong from a biological point of view; Timothy Shanahan (2004) generalizes Gould's anti-progress ideas and criticizes each of them from a philosophical point of view. In this paper, the author will systematically generalize Gould's central ideas and propose some new critiques that are different from the critiques of former biologists and philosophers.

\section{Gould's Arguments Against Evolutionary Progress}

\section{Human Arrogance Argument}

Gould believes that the concept of evolutionary progress is a product of human arrogance. He strongly favors one of Freud's ideas that almost all significant breakthroughs in the history of science are those that overthrow the pillars of human arrogance. The Copernican Revolution toppled geocentricism, wherein human beings believed that they lived at the center of the universe. However, the revolution showed that the earth is 
only a small planet moving around a star in a remote area of the universe. The Darwinian theory of evolution overturned creationism and showed that humans are not noble creatures created by God according to his own image but rather, that they evolved gradually from lower animals. Freud's unconsciousness theory shows that humans are not overly rational animals, as believed by previous scholars, but instead animals full of irrationality. Gould, after investigating biological history, believes that the second revolution mentioned by Freud has not been fully completed. According to the traditional theory of evolution, humans evolved from animals, and the whole history of evolution seems to show that the evolution of life developed from lower forms of life to higher ones, which eventually evolved into humans, who occupy the highest position in evolution. Gould thinks that this idea, in fact, serves only to add an imaginary development into the history of evolution to demonstrate human arrogance. He believes that the Darwinian revolution is great, yet not complete, and we need a fourth revolution to overthrow these mistaken ideas about the trends in evolution. He said:

This positive spin rests upon the fallacy that evolution embodies a fundamental trend or thrust leading to a primary and defining result, one feature that stands out above all else as an epitome of life's history. That crucial feature, of course, is progress - operationally defined in many different ways as a tendency for life to increase in anatomical complexity, or neurological elaboration, or size and flexibility of behavioral repertoire, or any criterion obviously concocted (if we would only be honest and introspective enough about our motives) to place Homo sapiens atop a supposed heap. (Gould, 2011, pp. 19-20)

Why are we so sure that the existence of humans is the inevitable and predictable result of evolution? Gould proposes that

We are driven to view evolution's thrust as predictable and progressive in order to place a positive spin upon geology's most frightening fact - the restriction of human existence to the last sliver of earthly time. With such a spin, our limited time no longer threatens our universal importance. We may have occupied only the most recent moment as Homo sapiens, but if several billion preceding years displayed an overarching trend that sensibly culminated in our mental evolution, then our eventual origin has been implicit from the beginning of time. In one important sense, we have been around from the start. In principio erat verbum. (Gould, 2011, p. 20)

Gould notes that findings of paleontology reveal that the history of humans only accounts for several "micro instants”, which leads to the fourth Freudian revolution: because human history is very short, and

if we are but a tiny twig on the floridly arborescent bush of life, and if our twig branched off just a geological moment ago, then perhaps we are not a predictable result of an inherently progressive process (the vaunted trend to progress in life's history); perhaps we are, whatever our glories and accomplishments, a momentary cosmic accident that would never arise again if the tree of life could be replanted from seed and regrown under similar conditions. (Gould, 2011, p. 18)

Therefore, Gould concludes that "progress is, nonetheless, a delusion based on social prejudice and psychological hope engendered by our unwillingness to accept the plain (and true) meaning of the fourth Freudian revolution” (Gould, 2011, p. 20).

\section{Anthropocentric Argument}

As for the existence of the concept of evolutionary progress, Gould believes that another closely linked explanation lies in the fact that humans impose their own subjective standards onto nature. Progress in biological evolution tends to be defined as some trends through which life's physiological structures become increasingly complex and its nervous system increasingly elaborate, behaving in areas that are more expanded and ways that are more flexible. We often use terms such as "from lower level to higher level" to describe 
progress in evolution. Yet what is lower level, and what is higher level? Gould says: "For if an amoeba is as well adapted to its environment as we are to ours, who is to say that we are higher creatures?” (Gould, 2007, p. 12) For Gould, lower level and higher level are judged by standards of human values, which is clearly anthropocentric. He notes that in Darwin's early books, there was no such word as "evolution" but there was "descent with modification”. Darwin first used "evolution” in The Descent of Man published in 1871. Gould argued that the reason why Darwin at first resisted the word is that in English evolution implies progress and development, and Darwin himself opposes the idea of equating evolution with progress. Gould also gathered some evidence from Darwin's notes and letters. For example, Darwin made a note in a book advocating progress theory: "Never say higher or lower"; in a letter to paleontologist Alpheus Hyatt from December 4th, 1872, Darwin wrote: "After long reflection, I cannot avoid the conviction that no innate tendency to progressive development exists” (Gould, 2011, p. 137).

If Darwin did not believe in progress, why did he begin to use the word "evolve" and even "progress" in his later version of The Origin of Species and other works? For Gould, the reasons mainly lie in Darwin's social status and the social circumstances in his time. Darwin came from a noble family that was radical in intelligence, liberal in politics, and conservative in lifestyle. Gould noted that

Darwin enjoyed this comfort in a society that, more than any other in human history, had enshrined progress as the fundamental doctrine of its meaning and being-Victorian Britain at the height of industrial and colonial expansion. How could a patrician Englishman, at the very apex of his nation's thundering success, abjure the principle that embodied this triumph? (Gould, 2011, pp. 140-141)

Gould then said:

Darwin, the intellectual radical, knew what his own theory entailed and implied; but Darwin, the social conservative, could not undermine the defining principle of a culture (at a key moment of history) to which he felt such loyalty, and in which he dwelt with such comfort. (Gould, 2011, p. 141)

Therefore, Gould concluded that

Darwin's view has triumphed among scientists who long ago abandoned the concept of necessary links between evolution and progress as the worst kind of anthropocentric bias. Yet most laymen still equate evolution with progress and define human evolution not simply as change, but as increasing intelligence, increasing height, or some other measure of assumed improvement. (Gould, 2007, p. 12)

\section{No Inner Thrust Argument}

Gould believes that the idea that evolution is progress implies that progress will be seen as the defining thrust of the entire evolutionary process (Gould, 2011, p. 146). It is this inner thrust that makes organisms inevitably evolve from lower level to higher level. However, there is no such pervasive or predictable thrust towards progress throughout the history of life, so it is false to say that evolution is progress (Gould, 2011, p. 146). Of course, if there existed such a thrust, it would be inevitable and hence predictable for life to develop towards higher levels. However, in common organisms, there is no evidence to support that there is a thrust to lead in the direction of evolutionary progress. Therefore, it is impossible for the evolutionary process of life to move towards the direction of progress.

\section{No Biological Mechanism for Progress Argument}

Gould believes that Darwin's natural selection does not mention pervasive progress or provide any 
mechanism to predict it. The theory of natural selection itself could not lead to progress. He demonstrated this with the example of the evolution of the Siberian mammoth. Because the weather in Siberia changed from an early mild climate to a later cold climate, an army of elephants with sparse body hair developed into mammoths covered with thick hair all over their bodies. Many years later, Siberia became the habitat for mammoths. Here, natural selection only produced changes in organisms that were adapted to the local environment. It did not produce changes that adapted to environments all over the world. Therefore, natural selection "yields only local adaptation, often exquisite to be sure, but not universally advancing” (Gould, 2011, p. 140).

Since natural selection only brings about local adaptation, why does Darwin make it clear in his later works that evolution is progress? Gould notes that Darwin puts forward an ecological explanation to make up for the logical loophole of natural selection. Darwin distinguishes two kinds of competition: biotic competition and abiotic competition. The former refers to competition between organisms for limited resources, while the latter means confrontation between organisms and their environment. Darwin argues that abiotic competition cannot trigger progress because the environment does not change towards a fixed direction. However, biotic competition could do so, as the best strategy to win the competition between two creatures of the same species is for progress in biological mechanisms to surpass the environment by running faster, enduring longer, thinking more carefully, etc. Darwin, therefore, believes that if biotic competition becomes more important than abiotic competition, the trend of pervasive progress should be true. He then demonstrates with a metaphor of "hammering wedges", in which nature can be seen as the ground and the species as the wedges that have been hammered in the ground. One driven-in wedge will inevitably force out another. Whether a wedge can be successfully driven into the ground mainly depends on the improvement of biological mechanisms. Darwin hence concludes:

The inhabitants of each successive period in the world's history have beaten their predecessors in the race for life, and are, in so far, higher in the scale of nature; and this may account for that vague yet ill-defined sentiment, felt by many paleontologists, that organization on the whole has progressed. (Darwin, 1859, p. 345)

For Gould, this argumentation only looks logical right on the surface, and he thinks that the Darwinian ecological argument about the predominance of biotic competition in a persistently full world is complex and dubious (Gould, 2011, p. 144). There are two reasons for this. One is that Darwin failed to provide a clear explanation; the other is that fossil evidence does not support this idea. A mass extinction will wipe out many species. After that, it is very unlikely for the habitat to be fully occupied by organisms. Therefore, the progress accumulated between any two mass extinctions will inevitably disappear in the next mass extinction, which is what Darwin is most afraid of. Gould says that Darwin has to deny mass extinction and claim that the idea of mass extinction results from incomplete fossil evidence. The fact is that mass extinction actually exists. For example, the extinction of the dinosaurs was caused by an alien planet colliding with the earth.

With respect to supporting evolutionary progress, Darwin's theory is not logically flawless. Why, then, does he still sneak the concept of progress into it? Gould argues that the reason is that Darwin's

strained and uncomfortable argument for progress arises from a conflict between two of his beings-the intellectual radical and the cultural conservative. The society that he loved, and that brought him such reward, had enshrined progress as its watchword and definition (I think of Herbert Spencer's famous essay "Universal Progress, Its Law and Cause”). Darwin could not bear to fail his own world by denying its central premise. Yet his basic theory required just this opposition. So he forged an escape, and concocted a tenuous resolution by scaffolding a separate argument about ecology onto an edifice that could not support the required proposition by its own unique and different strength. But buildings with 
scaffolds look messy and incomplete—-so why erect such a covering over a lovely structure that stands ever so well all by itself? I know no better illustration of the cultural power that progress holds over us than this story of Darwin's own unresolved intellectual struggle, this tug-of-war between the logic of his theory and the needs of his society. If Darwin could not liberate himself from this deepest presupposition of our shared culture even after inventing the theory with the key to this conceptual lock - then why should we be doing any better? (Gould, 2011, pp. 144-145)

Therefore, Gould makes it clear that

We may identify our assumption that evolution must entail progress as a cultural bias, and we may recognize that no good scientific argument for expecting progress exists, no more so in our own time than in Darwin's day. We may also acknowledge that all standard attempts, including Darwin's own, lie mired in social presupposition for the impetus, logical weakness for the argument, and factual inadequacy for the evidence. (Gould, 2011, p. 145)

\section{Extreme Contingency Argument}

Gould thinks that biological evolution does not have the internal thrust to develop towards the direction of progress. He believes that "the vaunted progress of life is really random motion away from simple beginnings, not directed impetus toward inherently advantageous complexity” (Gould, 2011, p. 173). For Gould, evolution is only related to extreme contingency. Because there is too much contingency in the history of life, biological evolution is unpredictable. In Wonderful Life, Gould asked: If evolutionary history could be replayed from the very beginning, similar to replaying a tape, what would happen? Would the same organisms appear again? Would human beings reappear after 400 million years? Would ants, crows, and magnolia trees emerge again? Gould believes it is quite unlikely. No matter how many times we could replay the tape of evolution, it would be unlikely to produce the same organisms that exist now (Gould, 1990, p. 51). Although in the later period of evolution, relatively complex organisms would surely appear,

the actual composition of creatures on the tail is utterly unpredictable, partly random, and entirely contingent-not at all foreordained by the mechanisms of evolution. If we could replay the game of life again and again, always starting at the left wall and expanding thereafter in diversity, we would get a right tail almost every time, but the inhabitants of this region of greatest complexity would be wildly and unpredictably different in each rendition-and the vast majority of replays would never produce (on the finite scale of a planet's lifetime) a creature with self-consciousness. Humans are here by the luck of the draw, not the inevitability of life's direction or evolution's mechanism. (Gould, 2011, pp. 174-175) (N.B. "left wall” and "right tail” are from Gould’s analysis using statistical terms.)

\section{Statistical Error Argument}

Gould thinks that the main tenant adopted by scholars advocating evolutionary progress is that some representative creatures are selected from complex life forms, then the typical creatures of each evolutionary stage will be recorded according to the following order: bacteria, fungi, plants, invertebrates, vertebrates, and human beings, which seems to suggest a trend in which life evolves from simple forms to complex ones, with progress being the most striking feature of the history of life. However, for Gould, such explanation and method of confirming trend are completely mistaken for many events that may seem to move towards a certain direction but are, in fact, just serial events at random. Hence, Gould argues,

In short, graspers for progress have looked exclusively at the history of the most complex organism through time- a myopic focus on extreme values only - and have used the increasing complexity of the most complex as a false surrogate for progress of the whole. But this argument is illogical and has always disturbed the most critical consumers. (Gould, 2011, p. 168)

Gould demonstrates this point with the example of a drunk person walking. A drunk person comes out of the 
bar and walks on the sidewalk in front of the bar. On one side is the wall of the bar and on the other side is the gutter. The drunk person staggers forward, swinging from one side to another. If he staggers long enough and entirely at random, what will happen next? The man will surely fall into the gutter because each time he hits the wall, he will be bounced back and move to the other side. However, when he gets close to the gutter, nothing stops him. Only one direction of movement remains open for him to continuously advance. He will certainly fall into it and become unconscious.

The above example shows that random motion without any specific direction could produce a certain result that does not necessarily indicate a fixed trend. The drunk person's motion is not controlled by any predestined rule, nor does it display any preference for one side. Gould argues there is some similarity between the history of biological evolution and the drunk person's walking. In the evolutionary process, species may develop towards simplicity or complexity. However, in the direction of simplicity, there is an insurmountable wall, for organisms cannot be more simplified than bacteria, while there is not such a wall on the side of being more complex. Therefore, for Gould, the increase in the average value of complexity in the process of biological evolution is just a byproduct of a random motion such as the drunk person's walking: "Similarly, some average or extreme measure of life might move in a particular direction even if no evolutionary advantage, and no inherent trend, favor that pathway" (Gould, 2011, p. 151).

Gould also uses the drunk person's walking to reinterpret the well-known Cope's rule of evolutionary biology. Edward Drinker Cope, an American paleontologist in the 19th century, arrived at a general principle concerning biological evolution that postulates that most creatures tend to increase in body size over evolutionary time. The traditional interpretation of Cope's rule is that having a larger body offers more advantages for organisms. Examples of these advantages include improved ability to capture prey or ward off predators, greater reproductive success, increased regulation of the internal environment, and increased heat regulation per unit volume. However, Gould thinks such an interpretation is totally misleading. On the one hand, the so-called advantages are just speculations by some biologists; on the other hand,

we note an increase in size of the largest species only because founding species start at the left wall, and the range of size can therefore expand in only one direction. Size of the most common species (the modal decade) never changes, and descendants show no bias for arising at larger sizes than ancestors. But, during each act, the range of size expands in the only open direction by increase in the total number of species, a few of which (and only a few) become larger (while none can penetrate the left wall and get smaller). (Gould, 2011, p. 162)

Therefore, for Gould, an increase in the body size of certain creatures is just the result of random evolution, rather than a fixed evolutionary direction. The theory of evolutionary progress always asks why creatures of large body size are favored by natural selection, while Gould's question is why species of small body size can survive every mass extinction and why every new evolution begins with several smallest species. The trend of increasing body size is, in fact, the product of the expansion of limited creatures. Thus, Gould argues that the mistake of scholars who favor evolutionary progress is that

apparent trends can be generated as by-products, or side consequences, of expansions and contractions in the amount of variation within a system, and not by anything directly moving anywhere. Average values may, in fact, stay constant within the system (...as the bacterial mode has remained for life)—while our (mis)perception of a trend may represent only our myopic focus on rare objects at one extreme in a system's variation (as this periphery expands or contracts). And the reasons for expansion or contraction of a periphery may be very different from causes for a change in average values. Thus, if we mistake the growth or shrinkage of an edge for movement of an entire mass, we may devise a backwards explanation. 
(Gould, 2011, p. 33)

\section{Bacteria Ruling the Earth Argument}

Gould proposes that in fossil records, all the earliest life forms are prokaryotes, or, loosely speaking, bacteria. In fact, half of the history of life on earth is about the story of bacteria. Life on earth started from the mode of bacteria. Bacteria still remain on earth, and in the future, bacteria will continue to live on earth. Therefore,

if we must characterize a whole by a representative part, we certainly should honor life's constant mode. We live now in the "Age of Bacteria”. Our planet has always been in the "Age of Bacteria”, ever since the first fossils-bacteria, of course were entombed in rocks more than three and a half billion years ago. ... On any possible, reasonable, or fair criterion, bacteria are—and always have been—the dominant forms of life on earth. (Gould, 2011, p. 176)

Bacteria have ruled the earth longer than any other forms of life and they are present in almost every corner of the world. Bacteria, hence, are the champions of stamina and dominators of the earth. Though humans are very powerful, it is beyond imagination that they could shake bacteria's status. Therefore, Gould says,

Bacteria have occupied life's mode from the very beginning, and I cannot imagine a change of status, even under any conceivable new regime that human ingenuity might someday impose upon our planet. Bacteria exist in such overwhelming number, and such unparalleled variety; they live in such a wide range of environments, and work in so many unmatched modes of metabolism. Our shenanigans, nuclear and otherwise, might easily lead to our own destruction in the foreseeable future. We might take most of the large terrestrial vertebrates with us-a few thousand species at most. We surely cannot extirpate 500,000 species of beetles, though we might make a significant dent. (Gould, 2011, p. 178)

This tells us that bacteria dominate the earth and they are the most adapted to the various settings on the earth, and therefore, it is bacteria, not human beings that are the most important organisms on earth. Thus, there is no progress evolving from bacteria to humans. As Gould says,

Full House presents the general argument for denying that progress defines the history of life or even exists as a general trend at all. Within such a view of life-as-a-whole, humans can occupy no preferred status as a pinnacle or culmination. Life has always been dominated by its bacterial mode. (Gould, 2011, p. 4)

\section{Critiques of Gould's Arguments}

\section{Evolutionary Progress Is Not the Demonstration of Human Arrogance}

Gould argues that those scholars who maintain that evolution is progress aim to prove that the emergence of the human race is the inevitable result of evolution, the whole history of evolution makes preparations for the emergence of the human race, and the human race, being the only purpose of evolution, stands at the top of evolution. In other words, humans are the most important creature in the world, even in the whole universe, because they are the most developed creatures - an idea that Gould firmly rejects. One important reason for Gould's firm rejection of this idea is that such a proposal may result in serious consequences:

This fallacious equation of organic evolution with progress continues to have unfortunate consequences. Historically, it engendered the abuses of Social Darwinism (which Darwin himself held in such suspicion). This discredited theory ranked human groups and cultures according to their assumed level of evolutionary attainment, with (not surprisingly) white Europeans at the top and people dwelling in their conquered colonies at the bottom. Today, it remains a primary component of our global arrogance, our belief in dominion over, rather than fellowship with, more than a million other species that inhabit our planet. (Gould, 2007, p. 12)

That is, the main reason Gould objects to the idea of evolutionary progress is based on axiology: It may lead to 
opinions inappropriate in today's culture. Gould's logic is that a belief in evolutionary progress may cause human arrogance and racism and even inequality among different species, and arrogance, racism, and inequality are morally wrong; thus, the idea of evolutionary progress is wrong. Such an argument is obviously untenable.

First, the idea that evolution is progress does not necessarily lead to the conclusion that evolution inevitably results in the emergence of humans who will then dominate the earth. Progress in evolution refers to the overall trend of evolution for all creatures to become increasingly complex and adaptive to the environment. Although this trend is certain, what creatures come out of the evolution process will be determined by the specific environmental conditions. If dinosaurs had not become extinct, there would have been no space left for some creatures later on, including humans. What is certain is that there would have been other complex life forms evolved. Therefore, Gould's argument that the progress of evolution necessarily leads to human arrogance is questionable.

Second, even if evolutionary progress presumes that humans will definitely come to occupy the summit of evolution, this is not necessarily followed by racism and inequality of species. Without human beings, the world would see more scenes of the law of jungle or survival of the fittest. The development of human civilization enables us to gradually understand the falsity of racism and the value of protecting biodiversity.

\section{Evolutionary Biology Can Have Value Terms}

Gould further argues that in nature, there is no such distinction between higher and lower levels. Such concepts as "higher" and "lower" are anthropocentric concepts; the idea of the development of creatures from a lower level to a higher level suggested by progressive evolutionists includes human value judgment and thus is not objective. From this, we can see that Gould opposes the use of value terms that carry subjective human intentions in biology. However, when criticizing evolutionary progress for having caused human arrogance, Gould has himself based his arguments on human value judgment. His logic is this: Because evolutionary progress might lead to racism and inequality of species, and, as we know, racism and inequality of species are morally wrong, evolutionary progress is not a good idea and is wrong. Here, Gould uses value judgment to evaluate evolutionary progress. Hence, Gould adopts a double-standard between judging his own argument against evolutionary progress and judging another person's argument for evolutionary progress. Gould himself uses value judgment to oppose evolutionary progress but he does not allow value judgment to be used by scholars who support evolutionary progress.

Gould's critique of the anthropocentric idea of evolutionary progress is not new. Early in 1932, J. B. S. Haldane had already said that "when we speak of progress in evolution we are already leaving the firm ground of objectivity for the shifting morass of human values” (Haldane, 1966, p. 56). Haldane and Gould's positions imply a radical dichotomy between scientific judgments, which are objective, and non-scientific judgments, which are subjective. Here, we meet one major methodological problem concerning evolutionary biology and, broadly speaking, general science: Can we use value-laden terms in science, especially in biology? Ever since David Hume, the fact/value dichotomy has been a methodological puzzle for science and the humanities. From Hume to modern logic positivists, many philosophers believe that value judgments should play no part in science because science must be objective.

In response to this fundamental methodological problem in the debate of evolutionary progress, we find two strategies in the history of biology and philosophy: One argues that we can avoid value terms and use 
purely objective terms to define progress; the other argues that value terms are legitimate in science because science is not value-free, and the radical fact/value dichotomy is wrong.

For the first strategy, we can see that some biologists, such as J. Huxley, J. M. Thoday, M. D. Sahlins, and R. Dawkins, try to propose an objective standard to determine what is considered progress in evolutionary theory. Huxley may be the best-known biologist who strongly supports the proposal of an objective concept of evolutionary progress. Huxley finds that in evolutionary history, the most salient fact is the succession of dominant groups. He says:

The distinguishing characteristics of dominant groups all fall into one or the other of two types: those making for greater control over the environment, and those making for greater independence of the environment. Thus advance in these respects may provisionally be taken as the criterion of biological progress. (Huxley, 1964, p. 562)

Thoday is another biologist who favors the formulation of an objective concept of progress. Thoday defines progress as an "increase of fitness for survival”:

increase of fitness, which is biological progress, must be brought about largely by changes which increase either genetic stability or variability without bringing about a corresponding decrease in the other component. A progressive change is thus one that increases the sum of these components. (Thoday, 1953, p. 99)

Sahlins is an anthropologist who also favors evolutionary progress. He proposes that the best criterion of "all-round progress" is a functional one: Higher organisms harness more energy than lower ones. Different levels of organisms have different ability to concentrate energy in their bodies and use energy to build and maintain the structures of organisms. Sahlins calls his criterion "thermodynamic achievement”. He applies this criterion not only to biological evolution but also to human cultural evolution. He says:

As in life, thermodynamic achievement has its organizational counterpart, higher levels of integration. Cultures that transform more energy have more parts and subsystems, more specification of parts, and more effective means of integration of the whole. Organizational symptoms of general progress include the proliferation of material elements, geometric increase in the division of labor, multiplication of social groups and subgroups, and the emergence of special means of integration. (Sahlins \& Service, 1960, pp. 35-36)

Dawkins believes that we can use objective terms to define progress. He defines progress as "a tendency for lineages to improve cumulatively their adaptive fit to their particular way of life, by increasing the numbers of features which combine together in adaptive complexes” (Dawkins, 1997, p. 1016). He thinks that this adaptationist definition of progress

takes progress to mean an increase, not in complexity, intelligence or some other anthropocentric value, but in the accumulating number of features contributing towards whatever adaptation the lineage in question exemplifies. By this definition, adaptive evolution is not just incidentally progressive, it is deeply, dyed-in-the-wool, indispensably progress. (Dawkins, 1997, p. 1017)

For the second strategy, we can also see some biologists and philosophers, such as C. J. Herrick, G. G. Simpson, and F. J. Ayala, try to legislate value terms in evolutionary biology. Herrick argues that the criterion for the concept of progress is an evaluative one: "An evaluation of some sort is necessarily implicit in the idea of progress" (Herrick, 1961, p. 124). He says,

The question, what is progress? then resolves into a matter of definition, and all definitions are made by human minds, not by the parasites that we study. All other scientific judgements are similarly subjective. It is only the observed facts that are objective. The scientific worth of any naturalist's opinion about what can be properly called progress can be gauged 
only by its operational utility in the interpretation of the known facts. (Herrick, 1961, pp. 124-125)

Herrick then defines progress as "Change in the direction of increase in the range, variety, and efficiency of adjustment of the organism to its environment and of the environment to the use of the organism” (Herrick, 1961, p. 125). Unlike Huxley, Thoday, and Sahlins, Herrick introduces value judgment in the definition of progress. He says,

We recognize a hierarchy of biological values which are in an organic relationship with enlargement and diversification of bodily structure, social organization, and ability to learn by personal experience. There is a similar progressive enhancement of values achieved in the human growth of every human child. In the lower ranks of animals and in the early infancy of a man most of these values are built into the hereditary structure and are biologically defined in behavioristic terms. In the higher animals and in the growing child there is an increasing proportion of learned skills and consciously recognized satisfactions which can be evaluated both biologically and psychologically. (Herrick, 1961, p. 140)

Simpson is another biologist who thinks that value judgment is legislative in biology. Similar to Huxley, Simpson believes that there is an objective concept of progress that can be formulated using objective functional criteria, such as reactiveness, awareness, and individualization. At the same time, he believes that there is a subjective concept of progress using subjective criteria of "approximation to man" or "evolutionary changes in the direction of man”. He says,

Among many possible definitions of progress, and many corresponding sorts of progress in evolution, that of change toward a particular sort of organism is as valid as any other as long as it is clearly understood to be specific with respect to a selected point and subjective in this sense. To man, evolutionary change in the direction of man is progress, of this particular sort. (Simpson, 1949, p. 262)

Simpson tries to combine two concepts of progress together. On the one hand, he wants to build objective criteria to determine what is considered progress; on the other hand, he appeals a subjective criterion to determine what is considered progress. Unfortunately, he does not analyze how to integrate them together. In this regard, Herrick seems to do a better job of explaining how to integrate them together.

Ayala realizes that the concept of progress contains two elements: "one descriptive, that directional change has occurred; the other axiological (= evaluative), that the change represents betterment or improvement" (Ayala, 1988, p. 78). Then, Ayala defines progress as "systematic change in a feature belonging to all the members of a sequence in such a way that posterior members of the sequence exhibit an improvement of that feature” (Ayala, 1988, p. 78). Or, simply speaking, progress is “directional change towards the better" (Ayala, 1988, p. 78).

According to the contemporary philosophy of science, there is no value-free science. For example, Thomas Kuhn believes that science is conducted by theoretical "paradigms"; S. Toulmin thinks that the "ideas of natural order" are important in determining what can be regarded as fact in science; I. Lakatos realizes that it is the "scientific research programme" that determines how to interpret scientific facts; Hanson states that all scientific facts are "theory-laden". Unlike logic positivists, none of these philosophers believes that there are pure facts in science. If we analyze the content of "paradigm", "ideas of natural order", and "scientific research programme”, we can find that there are value judgments in them. This means that in the practice of science, scientists must make judgments, and thus, no science is value-free.

According to the contemporary philosophy of value, the radical dichotomy of fact/value is completely wrong. This is clearly stated in John Dewey's philosophy. For Dewey, the fundamental shortcoming of the 
philosophy of value is its inability to bridge the gulf between science and value (Dewey, 1929). Dewey argues that evaluations must always be rooted in factual consideration and that the discrimination of facts always depends on evaluation. Stephen Pepper also strongly supports that there is no radical distinction of fact and value. In The Source of Value, Pepper uses the theory of natural selection to develop a value theory to explain how value originates from fact. He holds that natural selection functions according to evaluation, and thus we can say that "survival of fittest" can be seen as a value statement. He classifies all selective systems into seven categories with their accompanying values and finds that there are two basic, instigative, dynamic sources for the selective systems: instinctive purposive drives and vital forces of evolutionary selection (Pepper, 1958, p. 674). These two main dynamic agencies operate among the seven principal selective systems. The purposive drive operates on individual organisms; the force of selection operates on the reproductive process of an interbreeding population. Pepper believes that the first system generates affective values and the second system generates survival values. These two selective systems are autonomous sources of value. He says, "The survival values of natural selection as a natural norm are, of course, determined by the dynamics for adaptation of the species to its life zone or for its adaptability for filling some other available life zone” (Pepper, 1958, p. 677). Thus, we have two standards for evaluating evolutionary process: survival value, which is used for evaluating the course of evolution, which is innately applicable to a population, a species or some other unit of interbreeding organisms; and affective value, which is innately applicable to individual organisms. Because these two standards are used to evaluate different biological units, i.e., one for a group and one for an individual, in some situations, they will be compatible, and in other situations, they will be in conflict. If an evolution favors or compromises both group survival and individual affectivity, then this evolution is a progressive evolution.

From contemporary philosophies of science and value, we know that we cannot separate fact from value. It is impossible to avoid using value terms and judgments in science, especially in biology. In biology, fact and value are often combined. As Pepper already illustrated, the adaptive advantages of natural selection include value judgments. Of two or more groups of organisms, which is the more adaptive? When we say one group is more adaptive, it is a statement of fact, but at the same time, it is a statement of value, too. For the so-called survival of the fittest, we need to classify and evaluate which is fit and which is unfit. When we make a choice, we have already made a value judgment. In that judgment, there are facts, and there are values. Here, the facts and values are mixed together, and it is difficult to separate them.

Some biologists already know these philosophies. For example, to show his subjective concept of progress as legislative, Simpson says, "It used to be usual to claim that value judgements have no part in science, but we are coming more and more to perceive how false this was. Science is essentially interwoven with such judgements” (Simpson, 1949, pp. 311-312). Some biologists still do not know these philosophies but still correctly articulate their feelings for not abandoning value terms in biology. For example, famed evolutionary biologist T. Dobzhansky once commented in a letter to John C. Green:

I refuse to abstain from talking about progress, improvement, and creativity...In evolution some organisms progressed and improved and stayed alive, others failed to do so and became extinct...Yes, life is value and success, death is valueless and a failure...I cannot follow your advice and put these things in watertight compartments, and see only "change" and no "progress", only "change" and no "trial and error". For as a scientist I observe that evolution is on the whole progressive, its "creativeness" is increasing, and these findings I find fitting nicely into my general thinking. (Greene, 1962, pp. 12, 32) 
Unfortunately, some philosophers know these philosophies of science and value but still oppose evolutionary progress. Maybe they are influenced too much by traditional positive philosophy or they do not realize the important implications of these new philosophies. For example, Michael Ruse, a respected philosopher of biology, has written a whole book (Monad to Man: The Concept of Progress in Evolutionary Biology) talking about progress, but he denies that there is evolutionary progress. However, at the end of his book, he admits that if we banish value terms, we will banish many virtues of our present concept of evolutionary biology. He says:

At the purely conceptual level, evolutionary thinking of the most professional or mature level is still pervaded by metaphors sympathetic to progress, such as "tree of life," "adaptive landscape," and "arms race." Removing phrases like these might make for epistemic purity, but doing so would also banish many virtues, like predictive fertility, and surely result in epistemic sterility. (Ruse, 2009, p. 539)

We already showed that Gould's criticism of evolutionary progress as anthropocentrism is wrong. Remember that in his argument of progress as anthropocentric, Gould cites Darwin for not using evaluative terms such as "higher" and "lower" to demonstrate his idea. Now we go back to see whether his ideas about Darwin are right or not. As Gould himself already showed, in Darwin's later years, he began to use the word "evolve" and even "progress" in his later version of The Origin of Species and other works. Why did Darwin change his attitude? Gould thinks this is because Darwin wanted to make his own idea consistent with the mainstream ideology of his age, which claimed that progress was the goal of social development and the meaning of life. In other words, Gould thinks that Darwin proposed evolutionary progress because of his ideological considerations. The author believes that this is only Gould's speculation, and this kind of speculation is completely dubious. It is true that in Darwin's earlier writings, Darwin hesitated to conceive of evolution as progress, but as American philosopher Timothy Shanahan rightly shows in his book The Evolution of Darwinism,

As his confidence grew that the idea made sense, so, too, did his boldness in endorsing it in his writings. At first, he puts forth the view tentatively, with plenty of qualifications. By the end, he shows no hesitation in describing the evolutionary progress as progressive. (Shanahan, 2004, p. 177)

We will see the reason why Darwin theoretically adopted evolutionary progress later in Section "Natural Selection Can Serve as the Basis for Pervasive Progress” of this paper.

\section{No Pervasive Thrust Towards Progress Does Not Support the Rejection of Progress}

We completely agree that throughout the evolutionary history of life, there is not a pervasive or predictable thrust to promote progress, and progress is not the defining thrust in driving the whole process of biological evolution. However, not all thinkers who maintain that evolution is progress believe that progress is the crucial thrust of the evolution of life, which was advocated for only by Lamarckism and orthogenesis in the 19th century. Thus, the concept of evolutionary progress opposed by Gould is actually the concept advocated by Lamarckism and orthogenesis, not the concept of contemporary Darwinian progress. Both Darwin himself and the later Darwinists object to the idea that progress is the thrust that pushes biological life to evolve. They regard natural selection as the fundamental driving force. Progress, for Darwin, refers to a process in which new creatures evolve through natural selection because they become increasingly adapted to their various complicated environments by developing highly complex biological structures or improved biological behaviors. Gould mixes the Lamarckian concept of progress and the Darwinian concept of progress and allows 
people to think that these two concepts are actually one. Thus, according to him, if we see the wrongness of the Lamarckian concept of evolutionary progress, then we can abandon the Darwinian concept of progress as well. Relying on skillful rhetoric, Gould's arguments sound persuasive, but they are not. Currently, few people agree with the kind of evolutionary progress assumed by Lamarckism or orthogenesis. Gould actually sets up a nonexistent scarecrow and criticizes it, which simultaneously drags down the evolutionary progress of Darwinism.

\section{Natural Selection Can Serve as the Basis for Pervasive Progress}

The reason why Gould objects to the idea of evolution as progress is because natural selection cannot provide a basis for evolutionary progress. The author thinks this conclusion is obviously false. As Gould has noted, Darwin makes a distinction between abiotic competition and biotic competition. Abiotic competition may only cause local adaptations, as Gould says, but biotic competition can cause universal adaptations. Even if the former could not produce progress, the latter could.

In fact, Darwin was trying to prove that natural selection can lead to pervasive progress. This is noted by Gould. Thus, Gould states that Darwin is wrong in this regard. He then argues that Darwin's ideas about natural selection leading to progress lack evidence from paleontology. The reason is that in the history of life, there are mass extinctions, and these mass extinctions can annihilate all the accumulated progress. Here, Gould first admits that there is accumulated progress between two mass extinctions, and then he states that he believes that mass extinction wipes out such progress. However, the fact is that even a mass extinction only destroys part of all the organisms. Though this part of organisms might be a large part, it is quite unlikely that all organisms will be destroyed. Those organisms who survive the mass extinction will continue to evolve with their accumulated progress, and this progress may develop into long-term progress. Furthermore, based on Gould's punctuated equilibrium, there is mass explosion as well as mass extinction throughout the history of life. During the explosion period, a large quantity of new complex organisms will rapidly emerge, and these organisms have new features and exhibit progress.

It should be noted that in addition to the abiotic and biotic competition mentioned by Darwin, progress caused by natural selection may also be attributable to physiological and biochemical processes, body sizes, intelligence structures, and capacity of evolution, which have nothing to do with local environments. These features and capacities are not only adapted to local environments but are also adapted to non-local environments. Therefore, this kind of evolution belongs to general evolutionary progress.

\section{The Extreme Contingency of Evolution Does Not Make the Evolutionary Process Nonrepeatable}

Gould believes that due to the extreme contingency of biological evolution, the same evolutionary process cannot be duplicated, and humans are extremely unlikely to evolve if we replay the evolutionary tape. Thus, evolution should not be regarded as progress towards complex creatures. However, Gould does not deny that it is predictable for every replay to start with bacteria that develop into diverse creatures and eventually into increasingly complex creatures. Although every replay will be madly and unpredictably different, it is predictable that for each replay, evolution will lead to more complex creatures. Although it is unlikely for most replays to produce self-conscious creatures, it is inevitable that increasingly complex organisms will emerge. Therefore, evolution might not be a process of progress that inevitably leads to the emergence of human beings, but it will inevitably produce creatures that are increasingly complex. The emergence of human beings in the history of life might be a contingent result, but the emergence of another kind of creature similar to humans in the history of evolution would be inevitable. Therefore, biological evolution is not only directional but also 
develops towards the increasingly complex. The history of biological evolution is a history of evolutionary progress.

\section{Evolutionary Progress Is Not the Result of Statistical Errors}

Gould thinks that the increase of the average value of complexity in the evolutionary process is just a byproduct of random motion similar to the drunk person's walk, and it does not have any adaptive advantage. The emergence of a large body size is not due to a better adaptive advantage, but rather to the expansion of a few after mass extinction. He separates the increasing complexity of creatures from the adaptive advantages caused by natural selection. The increasing complexity of creatures is just a random motion of deviation from simple creatures and does not consequently gain any adaptive advantages. Therefore, evolution is not progress. However, the fact remains that although the motion towards a certain target is not predetermined, the target is after all achieved and the later creatures become more complex than their predecessors, which itself is progress. We cannot deny it simply because it is not predetermined. As discussed above, Gould, in fact, opposes the orthogenesis theory of evolution: Progress serves as the thrust to promote the evolutionary process, which most Darwinist biologists do not agree with. There are three key elements of the theory of natural selection: variation, selection, and heredity. Among these, variation is blind. That means there is no predetermined direction of evolution, but natural selection will eliminate those that are unfit and keep what is fit through the principle of survival of the fittest. Therefore, the denial of directional evolution does not imply that evolution is not progress.

In addition, Gould disparages the function of natural selection and denies that there are advantages gained due to those new features that organisms obtain through evolution. For Gould, there is no status of natural selection in the process of biological evolution, and he does not use advantages or disadvantages to explain the biological characters gained in the process of evolution. He thinks that this kind of thinking is adaptationist thinking and adaptationism is false (Gould \& Lewontin, 1979).

The author thinks Gould's disparaging of natural selection and complete denial of adaptationism is wrong. As we know, most contemporary evolutionists are Darwinian. They affirm the importance of natural selection in evolution, and they think that most of the characteristics gained through evolution have evolutionary advantages. Although strong adaptationism is wrong, weak adaptationism is widely accepted.

\section{Bacteria Ruling the Earth Does Not Imply That Bacteria Are Higher Than Human Beings}

Gould proposes that since bacteria are fitter than humans for all the various environments found on earth, humans are not higher than bacteria, and there is no progress evolving from bacteria to humans. It is true that the biosphere is filled with bacteria. They can be found in places where other creatures cannot live. However, as Gould himself admits, bacteria are the simplest creatures (except virus), and every other kind of organism is more complex than bacteria. Gould said that there is no internal force determining the evolution of bacteria into human beings, and this process is just the result of random movement. However, he does not deny that the complexity of organisms increases during the evolution of bacteria into humans. Gould convinces us that evolution is not determined, but he cannot convince us that evolution is not progress. The fact is, almost all contemporary Darwinists such as Gould deny that evolution is predetermined, but many of them do not deny that evolution is progress. As we can see, from bacteria to human beings, organisms become increasingly complex (structurally and functionally), which Gould also admits. There is no predetermined force for this process, and it is a progressive process. In other words, although bacteria rule the earth, human beings are 
higher than them, not only because human beings have more complex organic structures but also because human beings have abilities that are higher than those of bacteria. The evolutionary history of life from bacteria to humans is a history of constant progress.

\section{Conclusion}

The above analysis shows that Gould's idea that evolution is not progress is untenable. Gould thinks that the reason why biologists hold the idea of evolutionary progress is due to their ideological considerations. The author believes that most biologists who support evolutionary progress do not have an ideological purpose. They mainly base their biological conclusions on biological theories or facts. However, it is quite obvious that Gould's denial of evolutionary progress is due to his ideological purposes. He wants to use his biological thoughts to fight racism and anthropocentricism. To reach his ideological goal, he demonstrates that evolution is not progress. He first distorts evolutionary progress as Lamarckism and orthogenesis and then introduces his arguments. As we can see, contemporary scholars who advocate evolutionary progress also oppose Lamarckism and orthogenesis. It is indeed a great pity that Gould chooses these ideas to represent all the ideas of evolutionary progress. Gould denies that Darwin advocated for evolutionary progress and tries to prove that natural selection does not provide evidence for the overall progress of evolution. However, the fact remains that Darwin himself not only proposed evolutionary progress but also argued for overall progress based on natural selection, and that argument does not have any logical flaw, as was suggested by Gould. In addition, new argumentation in the perspective of natural selection has been offered in favor evolutionary progress. The extreme contingency of evolution proposed by Gould only explains that the same creatures cannot possibly emerge twice in evolution. This argument does not deny that evolution develops towards creatures that are increasingly complex and adapted to the environment. Gould's idea that evolution develops towards increasing complexity not because it is predetermined to do so but because it is the result of random motion, similar to a drunk person's walk, only shows that the direction of evolution is not fixed in advance-which effectively defeats Lamarckism and orthogenesis, but does not shake Darwinist progress, which argues that evolution is unpredetermined progress from lower creatures to higher ones. Gould regards bacteria, instead of humans, as the rulers of the earth because bacteria are more adaptive than humans. However, progress is manifested not only in high adaptiveness but also in the improvement in complexity of biological organization. Although humans cannot dominate the whole biosphere as bacteria do, they are much more complex than bacteria in terms of organizational structures and active abilities. In this sense, humans rule the earth, similar to bacteria. In conclusion, all the evidence provided by Gould in opposition of evolutionary progress is problematic and doubtful; the overall trend of evolution is progress, both in theory and in the judgment of facts from biological history.

\section{References}

Ayala, F. J. (1988). Can “progress” be defined as a biological concept. In M. Nitecki (Ed.), Evolutionary progress (pp. 75-96). Chicago: University of Chicago Press.

Darwin, C. (1859). On the origin of species by means of natural selection, or the preservation of favoured races in the struggle for life. London: John Murray.

Dawkins, R. (1997). Human chauvinism. Evolution, 51(3), 1015-1020.

Deway, J. (1929). The quest for certainty. New York: Minton, Balch \& Company.

Gould, S. J. (1990). Wonderful life. NY: W. W. Norton \& Company.

Gould, S. J. (2007). Ever since Darwin. NY: W. W. Norton \& Company. 
Gould, S. J. (2011). Full house: The spread of excellence from Plato to Darwin. Cambridge, Massachusetts: Harvard University Press.

Gould, S. J., \& Lewontin, R. C. (1979). The spandrels of San Marco and the Panglossian paradigm: A critique of the adaptationist programme. Proc. Roy. Soc., 205(1161), 581-598.

Greene, J. C. (1962). Evolution and progress. The Johns Hopkins Magazine, 32, 8-15.

Haldane, J. B. S. (1966). The cause of evolution. Ithaca: Cornell University Press.

Herrick, C. J. (1961). The evolution of human nature. New York: Harper.

Huxley, J. (1964). Evolution: The modern synthesis. New York: Wiley Science Editions.

Pepper, S. C. (1958). Source of value. Berkeley: University of California Press.

Sahlins, M. D., \& Service, E. R. (1960). Evolution and culture. Ann Arbor: University of Michigan Press.

Shanahan, T. (2004). The evolution of Darwinism: Selection, adaptation, and progress in evolutionary biology. Cambridge: Cambridge University Press.

Simpson, G. G. (1949). The meaning of evolution. New Haven: Yale University Press.

Thoday, J. M. (1953). Components of fitness. In R. Brown and J. F. Danielli (Eds.), Symposia of the society for experimental biology, VII, evolution (pp. 96-113). Cambridge: Cambridge University Press.

Thoday, J. M. (1962). Natural selection and biological progress. In S. A. Barnett (Ed.), A century of Darwin (pp. 313-333). London: Heinemann. 